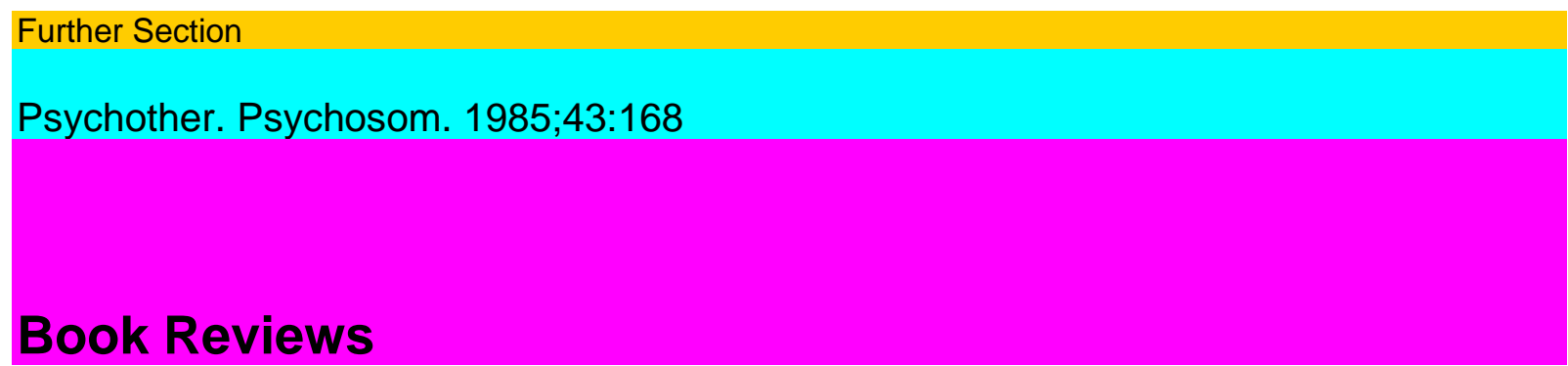

\title{
Hermann Argelander
}

Der psychoanalytische Beratungsdialog

Studien zur Textstruktur und Deutung an formalisierten Protokolltexten Vandenhoeck \& Ruprecht, Göttingen 1982415 pp.; DM58.-ISBN 3-525-45664

The author of this book entitled The psychoanalytic consultative dialogue. Studies concerning the text structure and interpretation on the basis of formalized record texts is Dr. Hermann Argelander, doctor and psychoanalyst, Professor and Chairman, Psychology Institute, University of Frankfurt. The contribution of Argelander and co-workers includes the aim to examine on the basis of formal criteria in which way unconscious meaning is evident in the psychoanalytic consultative dialogue; furthermore: on which basis the interpretations are formulated; finally: the differences between the psychoanalytic and the general interpretations as well as the relevance of the psychoanalytic interpretations within the dialogue with the patient. The authors define the term 'psychoanalytic consultation' in the sense of an attempt to present to the patient a decision matter vis-à-vis a difficult present life situation on the basis of the application of the psychoanalytic method. This decision making includes the aim to strengthen the patient's ability concerning an autonomous decision starting from both the patient's personality structure and the consultant's understanding on the basis of the present interactions.

Next to an extensive theoretical introduction the authors present their concept with regard to the for-malization and interpretation of records. Furthermore, the authors exemplify their concept on the basis of the following 5 examples: the dialogue between Sig-mund Freud and Dora, a dialogue between Rogers and his patient 'Gloria' as well as 3 consultative cases of the own project.

This informative book illustrates the dynamic and promising processes concerning the psychoanalytic consultative dialogue.

H. Freyberger, Hannover

F. Strian Angst

Grundlagen und Klinik

Springer, Berlin 1983

XVIII + 609 pp.; DM 148.-/US\$ 57.50

ISBN 3-540-12404-7

Dr. Friedrich Strian, the editor of this handbook which contains the psychological, social and biological aspects of the basic phenomenon 'Anxiety', is both Director, Neurologic Outpatient Department and Chief, Department of Psychophysiology, Max Planck Institute, Munich, FRG. Starting from the main title 'Anxiety: fundamentals and clinical aspects' the editor and 9 wellexperienced co-workers present a comprehensive concept which systematically includes both present research strategies as well as symptomatology, differential diagnosis and therapeutic possibilities. The reader is able to orient himself in an informative manner about the psychological, psychophysiological, neuroendocrino-logical, neuropsychological and neurophysiological aspects with regard to anxiety. Furthermore, specific clinically relevant 
aspects are presented, by which are exhaustively described both the various anxiety syndromes as well as the therapeutic procedures, particularly psychoanalytic and behavioral-medical techniques as well as psychopharmacotherapy.

E. Every colleague

who has to deal with patients suffering from anxiety

will profit from this book.

H. Freyberger

Hannover 